\title{
ANÁLISE DA METODOLOGIA NA PESQUISA JURÍDICA EM MIGUEL REALE
}

\author{
César Caputo Guimarães ${ }^{1}$
}

\section{RESUMO}

O presente trabalho, realizado mediante o estudo dos diferentes métodos na pesquisa jurídica, e a suma importância de debate sobre o estudo metodológico, no qual permite uma maior racionalização, compreensão e eficácia do Direito. Essa análise do tema será feita com base na proposta teórica de Miguel Reale do tema de metodologia jurídica, trazendo comparativos dos pensamentos em obras de outros autores relacionadas ao tema, expondo pontos de eventuais problematizações em torno da impossibilidade de se determinar tais critérios ao âmbito jurídico, outras vezes na tentativa de criação de uma sistematização de métodos próprios à Ciência do Direito.

PALAVRAS-CHAVE: Teoria Tridimensional. Métodos de pesquisa. Metodologia Weberiana. Cripto-normatividade. Ciência Jurídica.

\section{ANALYSIS OF MIGUEL REALE LEGAL RESEARCH METHODOLOGY}

\begin{abstract}
The present work, accomplished through the study of the different methods in the legal research, and the great importance of debate about the methodological study, in which it allows a greater rationalization, comprehension and effectiveness of the Law. This analysis of the theme will be based on Miguel Reale's theoretical proposal of the subject of legal methodology, bringing comparatives of the thoughts in works of other authors related to the theme, exposing points of possible problematization around the impossibility of determining such criteria to the legal scope, sometimes in an attempt to create a systematization of methods proper to the science of law.
\end{abstract}

KEYWORDS: Three-dimensional theory. Research methods. Weberian Methodology. Cryptonormativity. Legal science.

\footnotetext{
${ }^{1}$ Fundador do IBDEE - Instituto Brasileiro de Ética e Direito Empresarial e atualmente atua como membro de seu Comitê de Auditoria e como Coordenador de sua Comissão de Conformidade Penal; Membro do IASP Instituto dos Advogados de São Paulo, fundado em 1874 para melhorar o desenvolvimento da prática jurídica e científica.

Membro do Conselho Federal da Ordem dos Advogados do Brasil, como Membro de Estudos de Conformidade e também Presidente da Comissão Especial de Implementação da TV OAB, sendo responsável pela elaboração, estruturação e aprovação da criação da Rede Nacional de Televisão e Vice-Presidente da OAB da Comissão Especial do Mercado de Capitais, responsável pela criação da nomeação da OAB na Câmara de Apelações do Sistema Financeiro Nacional. ccaputo@almeidalaw.com.br
} 


\section{INTRODUÇÃO}

O termo "método" está diretamente associado à adoção de procedimento(s), técnica(s), para a realização de determinada atividade, seja essa intelectual ou manual. "Metodologia", por sua vez, é área da Ciência que se propõe ao estudo, à teoria - do grego logos - do(s) método(s).

Quando se trata do método orientado à pesquisa, há alguns já estabelecidos na doutrina científico-acadêmica há longa data: método indutivo, dedutivo, exploratório, quantitativo, qualitativo, entre outros.

No que diz respeito ao Direito, muito se debate sobre a utilização desses métodospadrões nessa área da Ciência. Autores brasileiros como Tércio Sampaio Ferraz Júnior, Miguel Reale e Luis Alberto Warat adentram na área da metodologia jurídica e a problematizam, algumas vezes em torno da impossibilidade de se determinar tais critérios ao âmbito jurídico, outras vezes na tentativa de criação de uma sistematização de métodos próprios à Ciência do Direito.

Uma das referências ao se tratar de metodologia científica é a obra de Umberto Eco intitulada "Como se faz uma tese", com a primeira edição sendo de 1977, lançada inicialmente em italiano (Come si fa una tesi di laurea: le materie umanistiche) e posteriormente traduzida em mais de 17 idiomas.

A obra de Eco, porém, mesmo sendo uma referência indubitável no assunto, apresenta uma metodologia pouco usual nos dias atuais, esses os quais estão locupletados de informação para todo o lado e que demandam uma resposta mais célere para as questões rapidamente mutantes e prementes em nossa vida prática. O preciosismo da minúcia que propõe Eco para a pesquisa não deixa de ser encantador para quem se propõe a estudar seu método. Além disso, há diversas outras contribuições nesse próprio livro que merecem consideração até os dias de hoje.

Porém, levar uma proposta consolidada e editada em obra de 1977 para a Ciëncia Jurídica atual, ao menos na parte prática dessa referida proposta, é confundir as possibilidades temporais e informacionais daquele tempo com as atuais, de dinâmica integralmente diversa, pelo menos se isso for realizado sem uma crítica contextualizada dos termos de Eco. 
Dessa maneira, no presente trabalho, por conta inclusive da enorme quantidade de trabalhos sobre o assunto, analisa-se mais a fundo a proposta teórica de Miguel Reale. Certamente, de forma paralela, outros autores entrarão nessa análise abaixo produzida, em especial Tércio Sampaio Ferraz Júnior e Luis Alberto Warat. Ademais, vale salientar que a centralização do debate nesses autores se dá tanto pela abrangência quanto pela densidade de seus estudos nessas áreas.

Cabe dizer que muitos manuais são redigidos no sentido de indicar métodos científicos de produção de textos jurídicos. Porém, a imensa maioria está focada na sustentação dos mesmos métodos utilizados em outras áreas, sem uma atenção especial às especificidades da área jurídica, como fazem os autores acima comentados.

Neste sentido, primeiramente são expostos os métodos mais comuns de uso na seara teórica da Ciência Jurídica, caminhando ao entendimento metodológico realeano. Para tanto, expõe-se o método compreensivo-normativo, trilhando da teoria de Max Weber à Miguel Reale, e, posteriormente, as posições de Tercio Sampaio Ferraz Júnio e Luis Alberto Warat em face da referida metodologia de Reale.

Por conta inclusive do debate estabelecido no presente trabalho ser a própria estrutura metodológica na Ciência Jurídica, mesmo que naturalmente implicado que, na introdução, seja indicado o método científico utilizado no presente trabalho, resolve-se por dizer que este se desenvolve aqui mediante uma metodologia analítica de cunho compreensivo sobre algumas das variáveis metodológicas de aplicação que são doutrinariamente relevantes do Direito pátrio, mediante pesquisa bibliográfica, nacional e internacional, considerando especialmente os autores suprarreferidos.

\section{DOS MÉTODOS INDUTIVO, DEDUTIVO, ANALÓGIO E DIALÉTICO AO ENTENDIMENTO METODOLÓGICO REALEANO}

Miguel Reale, jurista reconhecido especialmente pela sua Teoria Tridimensional do Direito, aborda a questão da metodologia científica no Direito através de uma ênfase à necessária consideração da interpretação, assim, claramente por consequência, da própria hermenêutica jurídica, para a determinação dos caminhos trilhados pelo cientista 
preocupado com problemáticas dessa seara da Ciência.

Um dos livros no qual expõe claramente tal proposição é o Lições Preliminares de Direito, cuja primeira edição é de 1973, mas ainda apresenta questões avançadas sobre o método jurídico-científico.

Ao conceituar os métodos dedutivo, indutivo e analógico, e suas correlações com a ciência jurídica, não deixa de salientar que que "todo conhecimento científico ou filosófico pressupõe uma ordenação intencional da inteligência e da vontade capaz de permitir ao investigador alcançar um resultado dotado pelo menos de relativa certeza" (REALE, 2001, p. 75).

Assim, para tanto, realiza comparações entre as ciências exatas, biológicas e humanas, afirmando o pressuposto de que as regras da lógica devem ser obedecidas por todas as áreas, mas que nem todas podem realizar verificações do tipo analítico - o qual estabelece o trabalho de pesquisa a partir da consideração de unidades completas de linguagem para, em seguida dividi-las em partes menores.

Para isso, exemplifica:

É o que acontece com as ciências físicas, químicas, biológicas etc., as quais realizam "verificações sintéticas", isto é, subordinam as suas hipóteses ao controle da experiência. É graças a processos de "experimentação", isto é, de experiências intencionalmente programadas e dirigidas, que os físicos ou biólogos verificam, em função dos fatos observados, o resultado de suas pesquisas. (REALE, 2001, p. 75-76).

Ou seja, nessas ciências, a obtenção de resultados, com base em experimentações empíricas, concretas, é que levam a conclusões de cunho o mais pragmático possível e em função de fatos diretamente observáveis, claramente se diferenciando do método analítico, pois se dissociam das unidades complexas (não totalmente, por óbvio, mas realizam um recorte), para a consolidação de situações, essas sim, cunhadas pela própria problemática a ser trabalhada. Porém, ao mesmo tempo, fomentando novos parâmetros de compreensão do mundo ao redor, conforme o direcionamento dado pela respectiva ciência em estudo.

Agora, voltando aos métodos suprarreferidos - indutivo, dedutivo e analógico Reale, nesse aspecto, se centra em conceitos mais conhecidos e utilizados (muitas vezes erroneamente) pela comunidade científica. Assim, esclarece cada um deles da seguinte 
maneira:

O método indutivo "se caracteriza por ser um processo de raciocínio que se desenvolve a partir de fatos particulares, até atingir uma conclusão de ordem geral, mediante a qual se possa explicar o que há de constante ou comum nos fatos observados e em outros da mesma natureza". (REALE, 2001, p. 77).

No mesmo sentido caminham Orides Mezzaroba e Cláudia Monteiro, para quem o método indutivo:

[...] permite que possamos analisar nosso objeto para tirarmos conclusões gerais ou universais. Assim, a partir, por exemplo, da observação de um ou de alguns fenômenos particulares, uma proporção mais geral é estabelecida para, por sua vez, ser aplicada a outros fenômenos. É, portanto, um procedimento generalizador. [...] O propósito do raciocínio indutivo é chegar a conclusões mais amplas do que o conteúdo estabelecido pelas premissas nas quais está fundamentado. (MEZZAROBA; MONTEIRO, 2009, p. 62).

Dessa maneira, nesse método, as disposições conclusivas, enquanto resultado de fenômenos constantemente reafirmados que, por isso, confirmam uma resposta a um determinado problema, evidentemente não sobressaem aprioristicamente. Assim, em outros termos, "o método indutivo fundamenta-se na generalização de propriedades comuns em determinado número de casos possíveis de ser observados em todas as ocorrências de fatos similares que sejam verificadas no futuro”. (MEZZAROBA; MONTEIRO, 2009, p. 64).

Já o método denominado “dedutivo" instrumentaliza uma lógica paradigmaticamente contrária ao indutivo, ou seja, parte de argumentos gerais que sejam verdadeiros e inquestionáveis (pressupostos claramente dogmáticos, portanto) para chegar em conclusões formais e que se constituem consequentemente em novas verdades.

Reale (2001, p. 77) explica esse método dizendo que:

[...] se caracteriza por ser uma forma de raciocínio que, independentemente de provas experimentais, se desenvolve, digamos assim, de uma verdade sabida ou admitida a uma nova verdade, apenas graças às regras que presidem à inferência das proposições, ou, por outras palavras, tão-somente em virtude das leis que regem o pensamento em sua "conseqüencialidade" essencial.

No mesmo sentido caminha Fonseca (2006, p. 8), ao salientar, em crítica, que "a 
lógica dedutivista opera uma metodologia racional, que, por sua vez, opera com base em um corpo de regras com "“pretensão e sentido universais"”.

Essa metodologia dedutiva, tendo em vista a noção instrínseca de pressupostos universais, remete claramente a um debate sobre o cunho valorativo e hermenêutico de suas bases constitutivas, o que será feito mais adiante quando for tratada a doutrina de Tercio Sampaio Ferraz Júnior sobre o pensamento realenano. Assim, levando em conta os aspectos subjetivos inerentes a esse método científico, é que Deisy Ventura (2005, p. 24-25), propondo afinal um "arsenal metodológico interdisciplinar" para a produção científica, salienta que, no método dedutivo, as normas ou propriedades de um objeto "são reconhecidas a partir de uma teoria que é aceita pelo sujeito que pensa. Para comprovar a pertinência deste modelo, há que verificar se as consequências dele deduzidas podem ser comprovadas pela experimentação ou pela aferição da realidade".

Agora, partindo para o método analógico, esse método é, no fundo, "um raciocínio baseado em razões relevantes de similitude”. (REALE, 2001, p. 79) A analogia tem um espectro que conduz ao pensamento e à teoria kantiana, no sentido de que, como bem desenvolvido por Leopoldo Fulgencio (2006, p. 208):

Para Kant, no que diz respeito ao uso das analogias nas ciências, elas são, num primeiro sentido, um tipo de regra para procurar algo que se desconhece em determinado fenômeno ou conjunto de fenômenos; um tipo de esquema para que se possa tentar descobrir um termo ainda não conhecido ou, ainda, descobrir relações desconhecidas a partir do que já é conhecido na experiência sensível.

A analogia, nesse sentido, é um tipo de método de pesquisa que procura buscar relações em comum entre institutos diversos. Esse método "torna possível procurar relações ou termos de uma relação. Na matemática, a analogia tem o poder de constituir o termo que falta, mas na filosofia e na ciência, ela tem apenas um papel regulativo, jamais um papel constitutivo daquilo que se procura”. (FULGENCIO, 2006, p. 208).

Como informa Reale (2001, p. 79), "quando encontramos uma forma de conduta não disciplinada especificamente por normas ou regras que lhe sejam próprias, consideramos razoável subordiná-la aos preceitos que regem relações semelhantes, mas cuja similitude coincida em pontos essenciais.

Para o referido autor, o processo analógico desempenha função relevante no 
Direito especialmente quando a lei é omissa e "não se pode deixar de dar ao caso uma solução jurídica adequada”. (REALE, 2001, p. 79).

Os métodos indutivo, dedutivo e analítico são alguns dos mais referenciados na academia. Outros autores extrapolam essa trilogia fornecendo outras formas de se pesquisar e consolidar um trabalho científico.

Mas, mais uma corrente que não pode deixar de ser enunciada é a o do método dialético, que se divide especialmente na corrente da dialética idealista hegeliana e no materialismo histórico dialético de Marx e Engels.

Em resumo, enquanto a dialética de Hegel trabalha com a famosa (mas nem tão realmente conhecida) teoria da tese-antítese-síntese, segundo a qual a progressão das ideias se faz através da sucessão desses três momentos, "o materialismo dialético entende que não existem oposições dualistas/dicotômicas entre as instâncias sociais e individuais, objetividade-subjetividade, interno-externo" (ALVES, 2010, p. 2).

A dialética hegeliana, como bem explicita Alvaro Marcel Alves (2010, p. 2):

É o método que permite ao pensador dialético observar o processo pelo qual as categorias, noções ou formas de consciência surgem umas das outras para formar totalidades cada vez mais inclusivas, até que se complete o sistema de categorias, noções ou formas, como um todo. A dialética hegeliana progride de duas maneiras básicas: trazendo à luz o que está implícito, mas não foi articulado numa ideia, ou reparando alguma ausência, falta ou inadequação nela existente.

Assim, a dialética idealista de Hegel, em breves termos, propõe certa determinação histórica, especialmente ao evocar a noção da já referida tríade, o que foi altamente criticado por Marx e Engels.

Marx e Engels, por outro lado, não negaram completamente Hegel, pois absorveram de seu pensamento a noção da "dialética", essa a qual se fundamenta igualmente no movimento, mas não mais num movimento ideológico, e sim materialista, histórico e não dotado de previsibilidade, requisitando a participação do sujeito na ação de construção da história.

Ou seja, o conceito fundamental em Marx e Engels é de que "o mundo não pode 
ser considerado um complexo de coisas acabadas, mas sim um processo de complexos. As coisas e suas representações refletem conceitos na mente, os quais estão em mudanças contínuas e ininterruptas de devir" (GOMIDE, 2014, p. 125). Dessa maneira:

[...] o materialismo histórico-dialético é um enfoque teórico, metodológico e analítico para compreender a dinâmica e as grandes transformações da história e das sociedades humanas. Conceitualmente, o termo materialismo diz respeito à condição material de existência humana, o termo histórico parte do entendimento de que a compreensão da existência humana implica na apreensão de seus condicionantes históricos, e o termo dialético tem como pressuposto o movimento da contradição produzida na própria história. (GOMIDE, 2014, p. 126-127)

Mesmo com essas divergências, que são afinal de nível axiológico, concorda-se, porém, num ponto, bem afirmado por Reale (1999, p. 29), de que "o pensamento é, em si mesmo, dialético, isto é, desenvolve-se dinamicamente atingindo estágios ou momentos que são, progressivamente, objeto de pesquisas de ordem analítica”.

\subsection{O MÉTODO COMPREENSIVO-NORMATIVO: DE MAX WEBER À MIGUEL REALE}

Max Weber (1864-1920), jurista e economista alemão, considerado, junto a Émile Durkheim (1858-1917), um dos fundadores da Sociologia, fez-se presente num momento histórico de dualidade entre positivistas (com suas origens em David Hume, Francis Bacon, entre outros), e os antipositivistas, nesses dentre os quais Weber se enquadrava e que se destinava, entre outros aspectos, a realizar diferenciações metodológicas entre os estudos das então chamada Ciências Naturais e as Ciências Humanas.

Como explica Marlon Tomazette (2008, p. 10):

Essa reação antipositivista cristalizou o entendimento no sentido da peculiaridade do fato humano que, por isso, necessitaria de uma metodologia própria. Essa metodologia deveria levar em consideração o fato de que o conhecimento dos fenômenos naturais é um conhecimento de algo externo ao próprio homem, enquanto nas ciências sociais o que se procura conhecer é a própria experiência humana, uma vez que, em ciências sociais, sujeito e objeto se confundem.

Revista de Pesquisa e Educação Jurídica | e-ISSN: 2525-9636 | Belém | v. 5 | n. 2 | p. 95 - 111 | Jul/Dez. 2019. 
Assim, para Max Weber, há diferenças fundamentais entre a compreensão dos fenômenos naturais e dos fenômenos sociais.

Para o referido sociólogo, os métodos relativos à matemática e suas respectivas proposições são os únicos capazes de apreender os fenômenos da natureza, esses os quais, através de análises relacionais e pela fixação de conceitos, seriam compreendidos de forma mediata.

Já os fenômenos sociais, por sua vez, mediante a subjetividade do agente e sua respectiva intencionalidade, são objeto de uma compreensão imediata: "quem compreende é capaz de explicar o fenômeno, sem necessitar de proposições gerais". (TOMAZETTE, 2008, p. 14).

Dessa maneira, Weber, influenciado por Simmel e Dilthey, reage ao naturalismo da época ao situar o conhecimento em termos de "compreensão", já que os fatos especificamente humanos possuem significados, os quais se opõem à descrição das já referidas ciências da natureza. Assim, a construção científica weberiana:

\begin{abstract}
[...] decorre da necessidade de Weber compreender a singularidade do social com o objetivo de chegar a uma ciência da ação social. O conhecimento do universal serve para explicar o indivíduo "histórico", daí os "tipos ideais"- do "capitalismo racional", "dominação patrimonial", "dominação burocrática" ou "cristianismo". (TRAGTENBERG, 1966, p. 173).
\end{abstract}

Nesse sentido, em relação às Ciências Humanas, Weber, na época de forma inovadora, entende que o sujeito que julga deva conformar-se aos critérios de "valor últimos que inconscientemente o movem, ou - para que fosse coerente - deveriam movê-lo". (WEBER apud WEISS, 2014, p. 120). O estabelecimento de tais critérios, portanto, afinal de contas, "é uma decisão pessoal, que concerne apenas à sua vontade e à sua consciência, não ao saber empírico". (WEBER apud WEISS, 2014, p. 120).

De forma extremamente relevante esclarece Weiss (2014, p. 120-121) o pensamento weberiano, nos seguintes termos:

[...] a questão da neutralidade axiológica aparece como um limite para atividade crítica da ciência, que pode mostrar ao indivíduo os valores últimos que os movem, mas não pode enunciar nada sobre a validade desses juízos, isto é, não pode emitir juízos de valor sobre os próprios juízos de valor a que se refere. A justificativa para isso pode ser entendida em termos de uma espécie de "divisão"

Revista de Pesquisa e Educação Jurídica | e-ISSN: 2525-9636 | Belém | v. 5 | n. 2 | p. 19 - 111 | Jul/Dez. 2019. 
dos campos do saber, entre o campo dos fatos, que compete à Ciência, e o campo da especulação que, conforme o caso, pode competir à Filosofia. Além disso, está pressuposta a ideia de que qualquer afirmação sobre valores últimos transcende o campo da experiência, isso porque, esta é a premissa de Weber, não existem, na realidade, valores que possam ser considerados últimos, fundamentais, universais. (grifo nosso)

Esse pensamento tem muita relação com a teoria epistemológica e metodológica de Luis Alberto Warat (1995, p. 57), para quem a ciência jurídica, “é sempre obscura, repleta de segredos e silêncios, constitutiva de múltiplos efeitos mágicos e fortes mecanismos de ritualização, que contribuem para a ocultação e clausura das técnicas de manipulação social" (mais adiante discorre-se mais especificamente sobre o entendimento de Warat, o qual é de acordo que a Ciência Jurídica o é assim igualmente por ser um discurso que determina um espaço de poder).

Assim, pode-se resumir o método compreensivo de Max Weber, o qual é estabelecido em oposição ao método explicativo das Ciências Naturais, apesar de ambos estarem condicionados à mesma inspiração racional, conforme Marlon Tomazette (2008, p. 15), com base em Julien Freund e Aluizio Amorim:

Dentro da metodologia weberiana, "o objetivo peculiar à compreensão é sempre captar o sentido de uma atividade ou de uma relação". Não se trata apenas de explicar um fenômeno, mas sim de captar seu conteúdo fundamental, seu sentido. "O sentido, nesse caso, é o responsável pela unidade do processo de ação e é somente através dele que poderemos apreender os nexos entre os enlaces significativos de um processo particular de ação e reconstituir tal processo numa unidade que não se desfaz numa poeira de atos isolados". Nesse tipo de análise, o motivo é o fundamento da ação e é fundamental para a análise sociológica.

Weber, dessa maneira, recorre aos chamados "tipos ideais", que não deixam se ser caracterizações, expressões subjetivas de noções de generalização, ideologias pode-se até dizer - ou seja, no ambiente debatido, que é o das Ciências Humanas, são noções sempre utópicas, pois que evidentemente não tem a capacidade de conglomerar a quantidade absoluta de fatos e dados mesmo que referentes a um mesmo processo epistemológico.

Mesmo assim, porém, esses “tipos ideais" se constituem em inovações já ao partirem da (cons)ciência de critérios subjetivos de determinado(s) pesquisador(es) da 


$$
\begin{array}{llllll}
\text { respectiva seara. Isso } & \text { de } & \text { fato } & & \text { fornece } & \text { instrumentos } \\
\text { metodológicos } & \text { ao } & & \text { estudo } & \text { do } & \text { Direito, principalmente ao }
\end{array}
$$

considerar a subjetividade como um aspecto ideal e ao contribuir para a diferenciação, ainda debatida, apesar de que atualmente em outros critérios sintáticos e semânticos, entre os métodos científicos utilizados nas Ciências Humanas e nas Ciências

Naturais.

Agora, vale a pergunta: qual a relevância do método compreensivo, conforme desenvolvido por Weber, para o método desenvolvido para o Direito no pensamento realeano? Miguel Reale Júnior, em sua obra Filosofia do Direito, explicitamente afirma se posicionar no sentido de Weber no momento em que esse sociólogo realiza a distinção entre ciências físico-matemáticas e ciências histórico-culturais através dos termos "explicar" e "compreender", como bem informa Reale (1999, p. 245-246):

\footnotetext{
Dizemos que explicamos um fenômeno quando indagamos de suas causas ou variações funcionais, ou seja, quando buscamos os nexos necessários de antecedente e conseqüiente, assim como os de interdependência, capazes de nos esclarecer sobre a natureza ou a estrutura dos fatos; e dizemos que o compreendemos quando o envolvemos na totalidade de seus fins, em suas conexões de sentido. É a razão pela qual as leis culturais não se desdobram gradualmente, umas relações resultando das outras segundo uma ordem progressiva de adequação aos fatos; elas antes se implicam e se pressupõem segundo uma exigência complementar, só encontrando confirmação por estarem inseridas numa trama congruente e coerente de enlaces ou conexões. (itálicos do original).
}

Dessa maneira, enquanto "explicar é descobrir na realidade aquilo que na realidade mesma se contém" (REALE, 1999, p. 246), ou seja, explicar tendo como essência a generalização e uma pertinência do respectivo fato em estudo a uma lei geral, a síntese realizada pelo cultor das ciências humanas em geral, quando enuncia uma lei sociológica ou uma norma jurídica, sempre traduz, "além da relação causal ou funcional peculiar ao suporte fático, a conexão de sentido ou, por outras palavras, a diretriz axiológica de desenvolvimento ou de obrigatoriedade resultante da 'tomada de posição' inerente a todo acontecimento social e histórico" (REALE, 1999, p. 249). 
Por esses motivos é que Reale (1999, p. 249) afirma que, ao invés das Ciências Naturais, as quais estabelecem sínteses explicativas, as Ciências Humanas, no denominador comum do seu âmbito de pesquisa científica, diferentemente, chegam a "sínteses compreensivas", considerando que a cada tipo de lei correspondem "critérios distintos de enunciação lógica e de rigor no tocante à sua verificabilidade".

Trilhando esse caminho, Reale vai concluir que o Direito é uma Ciência cuja metodologia básica é a compreensiva-normativa.

O porquê do termo "compreensivo" já foi explicado acima. Agora, é necessário o cotejo do termo "normativo", incluído por Reale quando se trata da Ciência Jurídica método compreensivo-normativo.

O método compreensivo de Weber tem uma funcionalidade peculiarmente interessante na sociologia, mas, para Reale, quando se trata do Direito, o critério normativo deve ser evidentemente incluído.

Isso porque tal método weberiano está carregado de dois pressupostos cujo paralelo com a filosofia jurídica tridimensional de Rela não pode ser negado, tendo em vista que a necessária identificação entre ambas as teorias, no caso tratando-se da esfera metodológica, se dá pela correlação intrínseca entre fatos e valores ao método a ser aplicado a determinada Ciência Humana.

Só que, para a aplicação do método de Weber especificamente à Ciência Jurídica (incluída essa, para Reale e outros, na seara da Ética), há a necessidade de inclusão dos aspectos sancionatório e deontológico do Direito.

Assim, enquanto "a sanção é algo que se acrescenta à norma, para a garantia de seu adimplemento, tal como ocorre no mundo jurídico ou no mundo moral" (REALE, 1999, p. 250), a esfera deontológica se justifica enquanto "compreender não é ver as coisas segundo nexos causais, mas é ver as coisas na integridade de seus sentidos ou de seus fins. segundo conexões vivenciadas valorativamente” (REALE, 1999, p. 251) - ou seja, há a necessária correspondência do jurídico ao dever-ser, em sentido e/ou em finalidade programática e ao mesmo tempo objetiva.

Assim, por esses motivos, para Reale, a Ciência do Direito deve ser conduzida através de um método compreensivo-normativo, ou seja, que incorpore as searas de fato, valor e norma (tridimensionalismo) em seu cotejo. 


\subsection{TÉRCIO SAMPAIO FERRAZ JÚNIOR E LUIS ALBERTO WARAT EM FACE DA METODOLOGIA DA CIÊNCIA JURÍDICA DE MIGUEL REALE}

Como bem salienta Ferraz Júnior (1969), as teorias jurídico-dogmáticas consistem a pesquisa num sistema preposicional que contém proposições ideológicas de natureza cripto- normativa.

A cripto-normatividade a que se refere Ferraz Júnior pode-se dizer que se sustenta consideravelmente na noção weberiana da já referida questão de que há sempre, pelo menos na esfera das Ciências Humanas, valores últimos e ocultos, que inconscientemente movem o sujeito e conferem à pesquisa dessas Ciências uma subjetividade intrínseca à análise e inerente à tal seara científica.

Tal autor vai salientar que na proposta de Reale se encontra fundante um critério objetivo, sendo que esse critério deve ser adotado na Ciência jurídica de maneira progressiva.

A objetivação da ciência para Reale, como ressalta Ferraz Júnior (1969), é "um sistema de proposições, leis e princípios, uma 'unidade das conexões fundantes', [...] proposições que têm por tema um determinado campo do ser".

Essa objetivação, assim, é orientada pela perspectiva kantiana de sua significação restrita ao que é posto, ao que funda, a um posicionamento específico sobre determinado mérito. Assim:

\footnotetext{
Na perspectiva transcendental, portanto, a ciência "é" sempre e tão somente a partir da atividade [...] de uma subjetividade constituinte. Miguel Reale concebe, porém, esta subjetividade na esfera do histórico, pois, para ele, a subjetividade constituinte é aquela do "Dasein" histórico do homem. Daí resulta um devir intencional, que tende, necessariamente, enquanto desenvolvimento, a um fim: a história do mundo deve, neste sentido, ser entendida em suas interpretações múltiplas como hermenêuticas dos diversos dados temporais, os quais se referem ao seu próprio vir-a-ser díalético- tensional. (FERRAZ JÚNIOR, 1969)
}

Nesse desenvolvimento metodológico de Reale, Ferraz Júnior vai salientar a perspectiva do último de que a própria jurisprudência é dotada de cientificidade, já que é 
uma possibilidade originária de síntese do pensamento jurídico.

No trabalho de Ferraz Júnior intitulado "Algumas observações em torno da cientificidade do direito segundo Miguel Reale" que é base para o presente capítulo, o autor conduz sua análise mediante principalmente a comparação entre o pensamento de Reale e de Theodor Viehweg, esse último que, em acordo com Reale, salientou que, para o Direito, a lógica dedutiva "seria própria de uma época, que considerou o papel da interpretação não como primordial, mas como secundário. Pois é, sem dúvida, evidente, que a interpretação tende a perturbar sensivelmente o rigor do sistema dedutivo" (VIEHWEG apud FERRAZ JÚNIOR, 1969).

Viehweg, como bem salienta Ferraz Júnior, vê a possibilidade de constituição de um "mínimo ideológico", o qual estaria "de antemão posto fora de todo e qualquer questionamento, teria sido dogmatizado de modo tecnicamente perfeito" (VIEHWEG apud FERRAZ JÚNIOR, 1969).

Esse tipo de determinação é uma negativa em absoluto da observação histórica, cultural e factualmente contextualizada conforme proposta por Miguel Reale. O dogmatismo presente nessa assertiva de Viehweg, conforme exposta por Ferraz Júnior, infere metodologias jurídicas dispostas a internalizar justamente o que Reale pretende demonstrar como constituinte do método científico jurídico, qual seja, a subjetivação imanente, a qual, inevitavelmente, ao expor a subjetividade como uma condição intrínseca à Ciência Jurídica, acaba não por excluir, mas sim relativizar a proposta dogmática, tanto de Viehweg quanto dos positivistas, especialmente os positivistas mais radicais.

Luis Alberto Warat, por sua vez, compreende que há no Direito um discurso interno, subjacente, mas não no sentido de Viehweg, esse o qual dispõe inclusive como necessária a construção da sua já referida "dogmática tecnicamente perfeita". Também, apesar da possibilidade de aproximações em alguns momentos com a teoria realeana, Warat, ao contrário, não vislumbra uma possibilidade de um Direito integralmente aberto ao debate histórico, cultural e socioeconômico, se concentrando na já disposta dialética marxista e afirmando, mediante principalmente críticas à ideia de pureza metodológica conforme adotada por Hans Kelsen, aqui nas palavras de Gilmar Antonio Bedin, que:

[...] como um imaginário de referência, se estabelecem as inibições, os silêncios e as censuras de todos os discursos da chamada ciência jurídica e que o mesmo funciona como uma espécie de racionalidade subjacente, como uma gramática de

Revista de Pesquisa e Educação Jurídica | e-ISSN: 2525-9636 | Belém | v. 5 | n. 2 | p. 95 - 111 | Jul/Dez. 2019. 
produção, circulação e reconhecimento dos discursos do direito [e da chamada ciência jurídica]. BEDIN, 2015, p. 191)

Dessa maneira, baseando-se no marxismo de Mikhail Bakhtin, intenta demonstrar, através do discurso da "carnavalização" (termo introduzido por Bakhtin) a necessidade de, mediante uma leitura lúdica do mundo, se "deslocar uma herança, subverter o ideal de uma ciência rigorosa e objetiva, estabelecer o caráter imaginário das verdades e compreender que, através do 'gênero' científico, nunca poderá efetivar-se a crítica à sociedade e reconciliar-se o homem com seus desejos”. (WARAT apud BEDIN, 2015, p. 191)

Warat, em sua crítica às posturas metodológicas em face do Direito, fornece instrumentos para uma relativização integral do conhecimento, especialmente no nível da subjetividade, a qual, quando não aberta ao novo, gera "a impossibilidade de se saber algo ou reconhecer sua existência, pois um espírito carregado de conceitos perde as asas para voar e as raízes que lhe possam outorgar identidade”. (WARAT, 2001, p. 23).

Assim, necessário (e também possível) para Warat o se despir dos seus conhecimentos, informações, vaidades, discursos e opiniões (WARAT, 2001), a fim de alcançar o conhecimento de forma clara e precisa, dialogando de fato com os demais autores e obras.

Vale dizer que a postura de Warat de fato parte de uma dialética (marxista) de cunho eminentemente histórico e social, possibilitando a produção de uma epistemologia e uma metodologia jurídica que forneçam questões centrais, nucleares, em face do estabelecimento do próprio Direito, não só enquanto Ciência mas também enquanto ordenador e regulador dos atos humanos.

\section{CONCLUSÃO}

Ademais, a construção realeana vai se fortalecer, principalmente nacionalmente, mediante a abordagem científica de outros doutrinadores brasileiros, que encontram em sua metodologia um relevante suporte para a Ciência Jurídica

De fato, sem um cunho generalista, importa referir que ainda é comum a construção de aportes acadêmicos que se dizem dedutivos mas que, de fato, estão mais ligado ao método compreensivo-normativo de Reale do que ao referido método científico 
dedutivo em seu sentido estrito.

E esse aspecto se faz relevante principalmente ao se observar a falta de orientação metodológica dos pesquisadores brasileiros em geral nas Instituições de Ensino Superior difundidas pelo país.

O debate sobre o método, o estudo metodológico, deve ser um dos pressupostos para a constituição não só de acadêmicos e pesquisadores do Direito, mas também daqueles que lidam constante e diariamente com os litígios. Diz-se isso pois a construção hermenêutica e lógica a partir de métodos científicos permite que a racionalização e a compreensão do Direito sejam mais eficazes e consistentes do que daquele que propõe soluções sem a devida consideração dos aspectos lógicos, axiológios e semanticamente coerentes com o sistema jurídico então vigentes.

Ferraz Junior, dessa maneira ao apresentar em sua pesquisa comparações entre o pensamento de Viehweg e Reale, aponta para este último como constituinte de um método científico-jurídico que esteja informado da subjetivação imanente, expondo, assim a subjetividade como uma condição intrínseca à Ciência Jurídica

Essa porém, conforme demonstrado, e uma premissa que deve ser atentada por Warat através de uma metodologia da complexidade, vinculada especialmente à face marxista do pensamento de Edgar Morin.

Evita-se, assim, para Warat, tanto na fundamentação quanto na conclusão da pesquisa, bases e respostas prontas e definidas direcionadas às nossas indagações. Warat, por outro lado, funda a sua metodologia em prol de rechaçar o chamado "pensamento mutilante", simplificador. Para isso, ciente de que a incompletude é intrínseca à pesquisa, Warat, baseado na dialética marxista, aborda um método sustentado na linha históricocrítica, em prol de desconstruir o subjacente na seara jurídica e evidenciar o que constantemente se pretende não ser revelado.

\section{REFERÊNCIAS}

ALVES, Alvaro Marcel. O método materialista histórico dialético: alguns apontamentos sobre a subjetividade. Revista de Psicologia da UNESP, v. 9, n. 1, 2010.

BEDIN, Gilmar Antonio. Luis Alberto Warat e a Epistemologia Jurídica: algumas reflexões sobre a trajetória intelectual de um jurista surpreendente. In: ROCHA, Leonel Severo; LOIS, 
Cecilia Caballero; MELEU, Marcelino. Cátedra Luis Alberto Warat. Florianópolis: CONPEDI, 2015.

FERRAZ JÚNIOR, Tércio Sampaio. Algumas observações em torno da cientificidade do direito segundo Miguel Reale. Revista Brasileira de Filosofia, v. XIX, São Paulo, p. 220230, 1969. Disponível em: http://www.terciosampaioferrazjr.com.br/?q=/publicacoes-

cientificas/21. Acesso em: 14 jun. 2019.

FONSECA, Dirce Mendes da. Paradigmas epistemológicos e práticas jurídico-científicas: uma análise da ideologia. 2006. Disponível em:

http://www.publicadireito.com.br/conpedi/manaus/arquivos/anais/manaus/ensino_jur_dirce_d a fonseca.pdf. Acesso em: 14 jun. 2019.

FULGENCIO, Leopoldo. O método analógico em Freud. Revista Estilos da Clínica, v. XI, n. 21, p. 204-223, 2006.

GOMIDE, Denise Camargo. O materialismo histórico-dialético como enfoque metodológico para a pesquisa sobre políticas educacionais. In: A crise do capitalismo e seus impactos na

educação pública brasileira. X Seminário de Dezembro. XII Jornada do Histedbr.

Maranhão, 2014.

MEZZAROBA, Orides; MONTEIRO, Cláudia Servilha. Manual de Metodologia da

Pesquisa no Direito. 5. ed., São Paulo: Saraiva, 2009.

REALE, Miguel. Filosofia do Direito. 19. ed., São Paulo: Saraiva, 1999.

REALE, Miguel. Lições Preliminares de Direito. 25. ed., São Paulo: Saraiva, 2001.

TOMAZETTE, Marlon. A contribuição metodológica de Max Weber para a pesquisa em Ciências Sociais. Revista Universitas Jus, Brasília, v. 17, jul./dez. 2008.

TRAGTENBERG, Maurício. O pensamento de Max Weber. Revista de História, São Paulo, v. 32, n. 65, p. 169-191, 1966.

VENTURA, Deisy. Do Direito ao método e do método ao Direito. In: por CERQUEIRA, Daniel; FRAGALE FILHO, Roberto. O papel das disciplinas propedêuticas no currículo dos cursos de Direito. São Paulo: Millennium, 2005.

WARAT, Luis Alberto. Introdução geral ao direito. Volume II. A epistemologia jurídica da modernidade. Porto Alegre: Sergio Antonio Fabris, 1995.

WARAT, Luis Alberto. O ofício do mediador. Florianópolis: Habitus, 2001.

WEISS, Raquel. Max Weber e o problema dos valores: as justificativas para a neutralidade axiológica. Revista de Sociologia Política, v. 22, n. 49, p. 113-136, Curitiba, jan./mar. 2014 